\title{
IMPLEMENTAÇÃO DO CONCEITO DE FAST TRACK EM UMA FERROVIA DE CARGA GERAL *
}

\author{
Breno Delgado Silva ${ }^{1}$ \\ Vinicius de Alvarenga Leal ${ }^{2}$ \\ Thiago Nunes de Castro ${ }^{3}$ \\ Jesus Jonatan Souza Santos ${ }^{4}$ \\ Gustavo Barros Castro \\ Breno Carvalho de Olveira ${ }^{6}$ \\ Lucio Flávio Drummond Matos ${ }^{7}$
}

\section{Resumo}

O conceito de Fast Track é a retirada das manutenções leves de dentro de oficina, migrando-as para realização em pátios, enquanto os vagões ainda estão no trem. A mudança de estratégia de manutenção para englobar este conceito aumenta 0 espaço disponível nas oficinas para realização de reparos pesados, reduz a quantidade de manobras para separar os vagões avariados dos em bom estado, reduz o número de vagões retidos e, consequentemente, aumenta a disponibilidade de ativos, melhorando a capacidade de escoamento do corredor. Através do projeto piloto no corredor Centro Leste a VLI conseguiu reduzir em $45 \%$ o envio de vagões para oficina, gerando um ganho de $0,44 \%$ na DF de vagões graneleiros.

Palavras-chave: Fast Track; Manutenção; Ativos Ferroviários.

\section{IMPLEMENTATION OF THE FAST TRACK CONCEPT IN A HEAVY HAUL RAILROAD}

\section{Abstract}

The Fast Track concept takes off the light maintenances of the workshops and takes them to railroads, in the wagons' standard path, with them still as a block. The change in maintenance strategy to encompass this concept releases spaces in the workshop to heavier activities, reduces the amount maneuvers for separate damaged wagons from those in good condition, reduces the number of retained wagons and, consequently, increases availability of assets, improving the runoff capacity of the corridor. Through the pilot project in Central East corridor, VLI was able to reduce by $45 \%$ the shipment of cars to workshop, gererating a gain of $0,44 \%$ in FD of bulk cars Keywords: Fast Track; Maitenance; Railway Assets.

1 Engenheiro de produção, Analista de processos de engenharia, Gerência de Engenharia de material rodante, VLI, Divinópolis, Minas Gerais, Brasil..

2 Engenheiro mecânico, Analista de processos, manutenção de vagões CL, VLI, Vitória, Espirito Santo, Brasil.

3 Engenheiro de mecânico, Analista de processos de engenharia, Gerência de Engenharia de material rodante, VLI, Divinópolis, Minas Gerais, Brasil..

4 Engenheiro eletricista, Supervisor de Engenharia de vagões, maquinas de via e materiais, Gerência de Engenharia de material rodante, VLI, Divinópolis, Minas Gerais, Brasil.

5 Engenheiro mecatrônico, Analista de processos de engenharia, Gerência de Engenharia de material rodante, VLI, Divinópolis, Minas Gerais, Brasil.

6 Engenheiro eletricista, Analista de processos de engenharia, Gerência de Engenharia de material rodante, VLI, Divinópolis, Minas Gerais, Brasil

7 Engenheiro de controle e automação, Analista de processos de engenharia, Gerência de Engenharia de material rodante, VLI, Belo Horizonte, Minas Gerais, Brasil. 


\section{INTRODUÇÃO}

A VLI (Valor da Logística Integrada) é uma empresa que oferece soluções logísticas integradas para seus clientes. O principal diferencial de seu modelo de negócio é o sistema totalmente integrado, com ativos próprios e de terceiros que conectam ferrovias, portos e terminais, assegurando uma operação mais ágil, segura e eficiente.

Para que a operação mantenha seu desempenho ótimo, é necessário que os ativos se mantenham funcionais. Tal objetivo é alcançado com a estruturação de uma política de manutenção adequada. Anteriormente a estratégia de manutenção de vagões baseava-se em intervenções corretivas e preventivas, com envio do dos ativos para oficina. Tal método diminuía bastante a disponibilidade dos vagões, pois era necessário o envio para oficina dos avariados para corretiva, e dos priorizados por tempo para preventiva. Da mesma forma havia grande perda de tempo devido as manobras necessárias para o fracionamento do trem.

Através de benchmarking em ferrovias americanas identificou-se a oportunidade de melhoria da estratégia de manutenção através do modelo de Fast Track. Este consiste no aproveitamento do tempo morto dos vagões após descarga na moega ou pátios intermediários para a realização de intervenções rápidas. Com a aplicação desta metodologia objetiva-se a redução de $45 \%$ do envio de vagões para oficina.

\subsection{Conceitos de manutenção}

De acordo com Pinto e Xavier [1], a manutenção tem como missão garantir a disponibilidade dos equipamentos, a confiabilidade e segurança da operação com o menor custo possível.

As técnicas de manutenção mais utilizadas são a corretiva, preventiva e preditiva. Recentemente alguns conceitos vem crescendo como a Manutenção Produtiva Total (MPT), a Manutenção Centrada em Confiabilidade (MCC) e a Manutenção de classe Mundial (MCM).

A Manutenção Corretiva (MC) é caracterizada pela atuação devido a uma falha súbita do componente ou equipamento. De acordo com Pinto e Xavier [1], é realizado para corrigir uma falha ou desempenho menor que o esperado. Esta pode ser programada ou não programada.

De acordo com a NBR 5462 [2], a Manutenção Preventiva (MP) é realizada em intervalor predetermina, com um critério preestabelecido, de forma a reduzir a probabilidade de falha ou degradação dos itens em operação. Para a Lopes [3] a MP é baseada em dois princípios: que há um estreita relação entre a idade do equipamento e sua taxa de falha, e que a vida útil do componente pode ser estimada por métodos estatísticos, de forma que este pode ser substituído antes da falha.

A Manutenção preditiva é o monitoramento contínuo, ou em intervalos de tempo, de certas características dos equipamentos ou peças. Através deste é possível estimar a vida útil do componente com grande assertividade, sendo possível antecipar quando o será necessária intervenção no sistema, aumentando a disponibilidade 
dos equipamentos, reduzindo paradas emergenciais e aumentando a vida útil e confiabilidade do sistema [4].

\subsection{Estratégia de manutenção VLI}

A estratégia de manutenção da VLI é baseada em três tipos de manutenção, classificadas como inspeção (visual / sensitiva nos pátios e terminais), manutenção corretiva (programadas e não programadas) e manutenção preventiva (contemplando inspeções de integridade estrutural) [5].

Esta estratégia vem sendo remodelada para atuação condicional, através da implantação de uma manutenção preditiva, na qual os ativos são monitorados por equipamentos Waysides, elevando o número de tipos de manutenção para 4.

O processo de inspeção é realizado em pátios, linhas de sinalização, estações de carga e descarga e oficinas, onde as condições dos componentes dos vagões são verificadas, visando principalmente a segurança operacional e sua funcionalidade. Sempre que uma anomalia é identificada o vagão é então destinado para manutenção, e pode ser classificada como corretiva programada ou correção emergencial.

As manutenções corretivas podem ser programadas para serem realizadas em oficina, ou não programadas, a ser executada assim que uma falha for identificada em um pátio ou oficina.

A manutenção preventiva é definida por um intervalo de tempo, em que ocorre a verificação, qualificação e correção de componentes. Estas etapas são realizadas de forma a retornar os componentes a padrões predefinidos, garantindo boa performance operacional e maior confiabilidade.

$\mathrm{Na}$ atuação preditiva a VLI utiliza equipamentos de detecção acústica de defeitos em rolamentos, o qual indica o nível de desgaste superficial dos componentes do rolamento, informando quando este não é mais adequado para uso, e também utiliza detectores de Hot Box, que informam a temperatura do rolamento, evitando ocorrências ferroviárias severas. Há também equipamentos para avaliação da performance dos truques, que indicam folgas e desajustes no sistema. Para avaliação das rodas dos vagões há equipamentos que realizam aquisição do perfil da roda, verificando suas condições geométricas, verificação do impacto de roda, indicando presença de calos e escamações nas rodas e detectores de temperatura, que indicam o funcionamento correto do sistema de freios. Estas técnicas de monitoramento de ativos somam-se as técnicas passa - não passa de liquido penetrante, que é aplicada em oficia nos adaptadores e laterais dos truques, e a avaliação por ultrassom que é realizada nos eixos.

\subsection{Manutenção fora de oficina}

O conceito de manutenção fora de oficina, chamado de Fast Track VLI, foi desenvolvido com base em benchmarking em outras ferrovias. Para adoção desta estratégia é necessário que os vagões cheguem inspecionados nos pátios de 
manutenção, de forma que o time de manutenção volante possa se deslocar para a linha em que o vagão não-conforme está.

O sistema de manutenção Fast Track é realizado nos vagões em pátio, no trem completo (RUN THROUGH nos Estado Unidos). Este conceito foi adaptado aproveitando o tempo morto dos vagões após descarga para realização de intervenções rápidas, método conhecido como Pit Stop / Manobra Zero.

Devido as limitações de tempo e espaço nas moegas para realização de todas as atividades do Fast Track, foram delimitados algumas linhas no Terminal de Produtos Gerais (TPD) para acomodar os blocos de vagões críticos, que não foi possível manutenir nas moegas. Estas linhas possuem uma área preparada para realização das atividades de médio reparo, como troca de rodeiros, reparações com maçarico e solda, substituição de componentes, etc.

Após realização dos reparos, caso exista algum vagão no bloco que necessite de envio para oficina, a operação retira todo o bloco e sapara estes vagões no pátio, que são então direcionados para oficina mais próxima, reduzindo a necessidade de manobras nas moegas.

O Unit Train é um local descoberto próximo a oficina onde uma variedade de reparos podem ser executados. No conceito americano estas linhas possuem uma área preparada para manutençãi de truques, como troca de triangulo, pequenos reparos no conjunto de choque e tração (CCT) e a substituição do truque completo caso seja necessário.

O Standard Repair Track são as oficinas cobertas, que são utilizadas para reparos pesados. As intervenções que ocorrem em oficina são classificadas através do mapeamento de $100 \%$ das atividades pelo inspetor, banco de dados e monitoramento pelos equipamentos Waysides. A Figura 1exemplifica os conceitos do novo modelo de manutenção. 


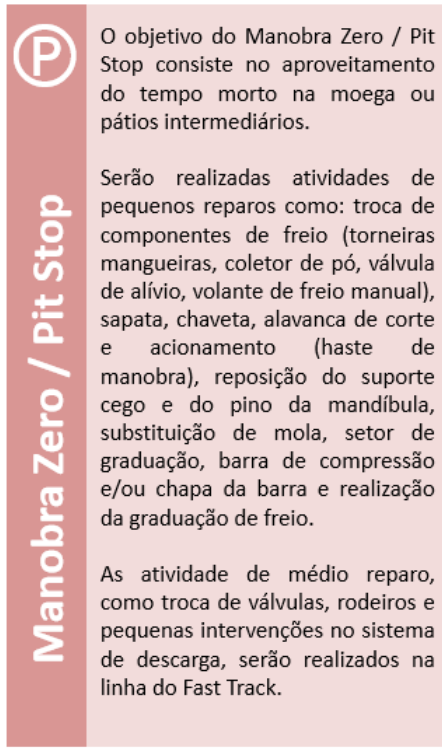

Denominações: Pit Stop / Manobra Zero, Atividades de reparo rápido.

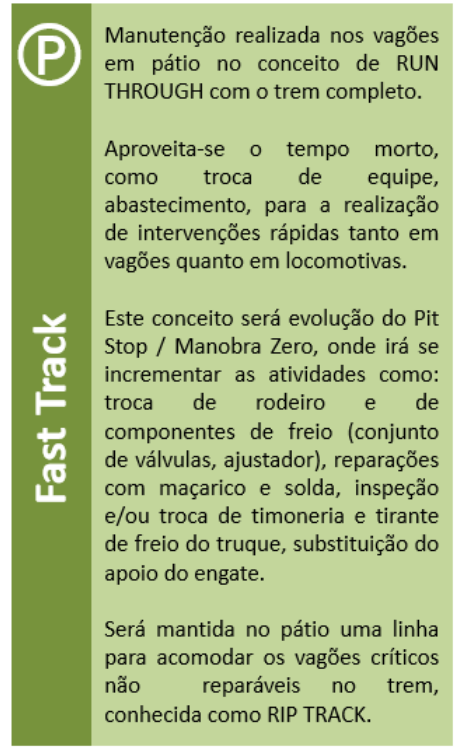

Denominações: Fast Track, Track Service, Manutenção on Track, Run Through, Manobra Zero, Pit Stop, Equipe Volante.

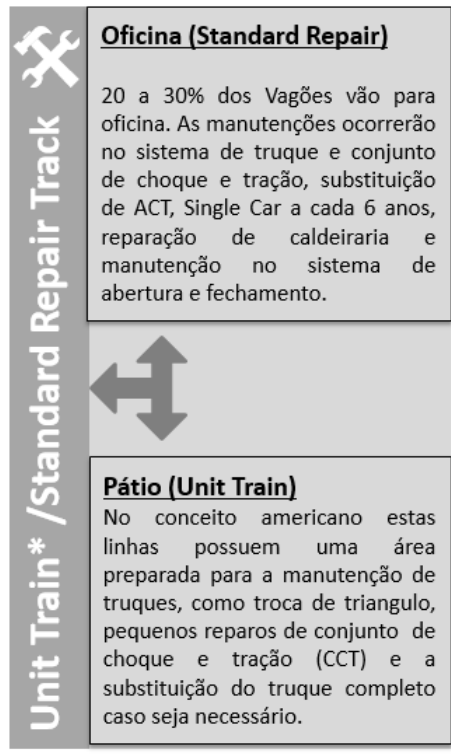

Denominações: Unit Train, Unit Train Track, Standard Repair Track, Oficina, Pátio, Manutenções.

*Unit Train: Local descoberto, próximo a alguma oficina, onde uma variedade de reparos pode ser executada, mas nenhuma troca de material/componente é planejada. Em alguns casos não será disponibilizada a linha de Unit Train pois os vagốes serão destinados diretamente a oficina.

Figura 1. Definições do modelo de manutenção.

\section{MATERIAIS E MÉTODOS}

Para atingir os objetivos do projeto, as responsabilidade foram definidas por área de atuação, distribuindo-se tarefas entre estas. Entre as principais responsabilidades destacam-se:

- Engenharia:

- Definir as diretrizes, atividades e recursos básicos para implementação;

- Revisar os fluxos de processos;

- Revisar o escopo e duração das atividades;

- Definir a estratégia de manutenção;

- Criar as instruções de trabalho e plano de certificação;

- Adquirir os equipamentos necessários para o Fast Track.

- Manutenção de vagões:

- Atualizar as informações sobre os ativos no sistema de manutenção;

- Assegurar a visibilidade e legibilidade da identificação física dos vagões;

- Realizar a manutenção de acordo com a estratégia.

A partir da divisão de responsabilidades as principais etapas do projeto foram:

- Definição do local de implantação;

- Definição da demanda de manutenção;

- Definição do local e layout;

- Definição dos recursos necessários;

- Criação do plano de certificação e capacitação. 


\subsection{Definição do local de implantação}

Para definição do local do projeto piloto avaliou-se a quantidade de vagões e o volume orçado por corredor. Com base nessa análise escolheu-se o corredor Centro Leste, cujo esquemático simplificado pode ser visto abaixo na Figura 2.

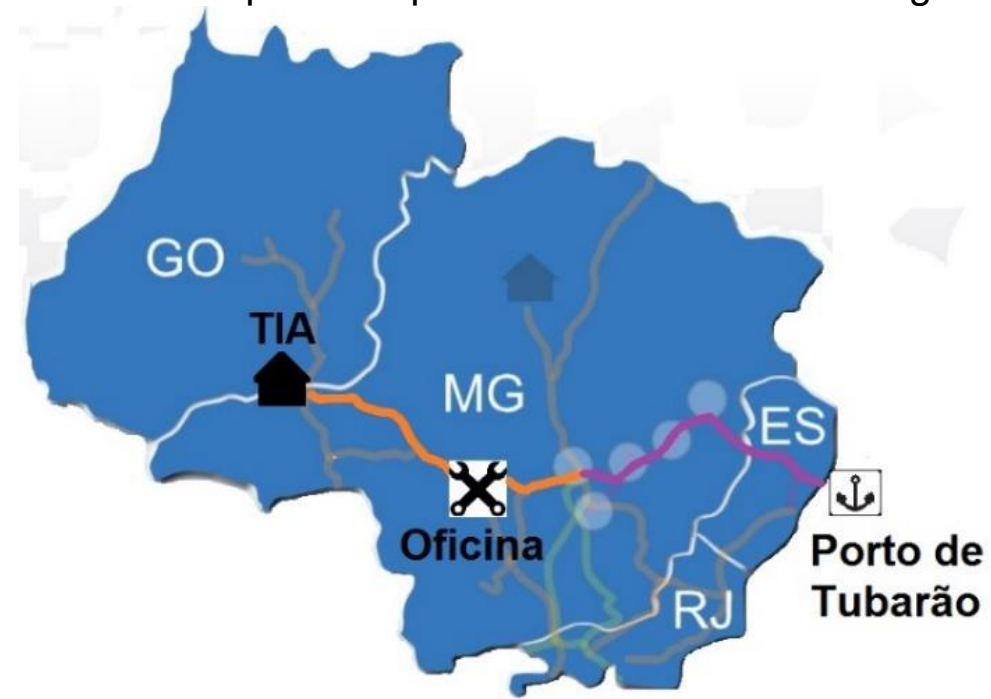

Figura 2. Estrutura simplificada do fluxo do corredor Centro Leste.

Este corredor suporta a demanda da indústria siderúrgica e a exportação de grãos pelo complexo de Tubarão, bem como cargas de carvão, fertilizantes e combustíveis. O carregamento de grãos é realizado no Terminal Integrador Araguari (TIA), seguindo por um trecho de aproximadamente $1500 \mathrm{Km}$ até o porto de tubarão, no qual a VLI agencia as moegas 2 e 3.

Devido ao tempo morto durante a descarga dos vagões nas moegas, escolheu-se a gerencia de manutenção de vagões de Itacibá como responsável pela execução. Dessa forma as intervenções leves podem ser realizadas no pátio do complexo portuário, enquanto que manutenções mais pesadas podem ser redirecionadas para a oficina de Itacibá, localizada na cidade de Cariacica.

Esta escolha atua na redução do tempo de viagem do vagão para oficina, sendo o tempo médio de viagem do trecho Tubarão - Divinópolis de 7 dias, enquanto que o Tubarão - Itacibá de 1,5 dias.

\subsection{Definição da demanda de manutenção}

A demanda de manutenção trabalhará de acordo com o fluxo de descarga nas moegas 2 e 3 . Durante o processo de descarga os vagões serão inspecionados e classificados de acordo com o tipo de manutenção.

A moega 2 tem capacidade de descarregar 4 vagões, carregados com 70 toneladas de grãos cada, a cada 15 minutos, enquanto que na moega 3 descarregam-se 5 vagões com a mesma capacidade a cada 15 minutos. Dessa forma o tempo limite para Pit Stop é de 15 minutos. 
Através de base histórica de falhas identificadas nos vagões na moega, verificou-se que em média 10,8\% da composição apresentava alguma não-conformidade. Esta taxa pode ser relacionada com o número de vagões na composição, sendo então estimada que um vagão a cada 2 puxadas (entrada de novos vagões para descarga), apresentará defeito, tendo a equipe de mecânicos 15 minutos para reparação.

\subsection{Definição da demanda das atividades}

A partir do estudo da estratégia atual da VLI, considerando o que é executado em oficina e o que poderia ser transferido para os pátios, definiu-se o portifólio de atividades a serem aplicados no Fast Track.

As atividades apresentadas nas tabelas 1 e 2 foram detalhas previamente com a gerencia de manutenção para avaliar o tempo de execução, e com base nestes dados, estimar também a quantidade de executantes e recursos necessários.

Tabela 1. Atividades Pit Stop / Manobra Zero

\begin{tabular}{|c|c|c|c|}
\hline MANOBRA ZERO / PIT STOP & MíNIMO & MÉDIO & MÁXIMO \\
\hline Freio Rápido & $00: 14: 58$ & 00:19:58 & $00: 24: 57$ \\
\hline $\begin{array}{l}\text { Troca de Componentes de Freio (Torneiras Mangueiras, Mangueiras, Coletor de } \\
\text { Pó, Válvula de Alívio, Volante de Freio Manual) }\end{array}$ & $00: 15: 00$ & 00:20:00 & 00:25:00 \\
\hline Reparação e/ou Substituição de DDV & 00:05:00 & 00:07:00 & 00:10:00 \\
\hline Reposição do Suporte Cego & 00:01:00 & 00:02:00 & 00:03:00 \\
\hline Truque Rápido & 00:05:26 & 00:08:10 & $00: 10: 53$ \\
\hline Substituição de Mola & $00: 10: 00$ & 00:15:00 & $00: 20: 00$ \\
\hline Substituição Setor de Graduação & 00:02:00 & 00:04:00 & 00:05:00 \\
\hline Substituição Barra de Compressão e/ou Chapa da Barra & 00:02:00 & 00:04:00 & 00:05:00 \\
\hline Chavetas; & 00:04:00 & 00:06:00 & 00:08:00 \\
\hline Sapatas & 00:04:00 & 00:06:00 & 00:08:00 \\
\hline Realizar Graduação de Freio & 00:03:00 & 00:05:00 & 00:07:00 \\
\hline ССТ Rápido & 00:02:01 & 00:03:01 & 00:05:00 \\
\hline Reposição Pino da Mandíbula & 00:02:00 & 00:03:00 & 00:05:00 \\
\hline $\begin{array}{l}\text { Reparação e/ou Substituição de Alavanca de Corte e Acionamento (Haste de } \\
\text { Manobra) }\end{array}$ & 00:03:00 & 00:04:00 & 00:05:00 \\
\hline
\end{tabular}

Tabela 2. Atividades Fast Track

\begin{tabular}{|l|c|c|c|}
\multicolumn{1}{|c|}{ FAST TRACK } & MÍNIMO & MÉEIO & MÁXIMO \\
\hline Superestrutura Médio & $00: 50: 00$ & $01: 30: 00$ & $02: 40: 00$ \\
\hline Reparações com maçarico e soldas (Sem necessidade de trabalho em altura); & $00: 50: 00$ & $01: 30: 00$ & $02: 40: 00$ \\
\hline Freio Médio & $00: 18: 12$ & $00: 25: 33$ & $00: 32: 54$ \\
\hline Teste de Aplicação de Freio (Analise de Freio Isolado ou Não Aplica); & $00: 05: 00$ & $00: 10: 00$ & $00: 15: 00$ \\
\hline Troca de Componentes de Freio (Conjunto de Válvulas, Ajustador), & $00: 15: 00$ & $00: 20: 00$ & $00: 25: 00$ \\
\hline Substituição do Freio Manual & $00: 20: 00$ & $00: 25: 00$ & $00: 30: 00$ \\
\hline Teste de Single Car (Para Corretiva); & $00: 45: 00$ & $01: 00: 00$ & $01: 15: 00$ \\
\hline Truque Médio & $00: 15: 00$ & $00: 25: 00$ & $00: 35: 00$ \\
\hline Inspeção e/ ou Troca de Timoneria e Tirante de Freio do truque & $00: 15: 00$ & $00: 25: 00$ & $00: 35: 00$ \\
\hline Rodeiro Médio & $00: 10: 00$ & $00: 20: 00$ & $00: 40: 00$ \\
\hline Troca de Rodeiro por (Friso fino / Bandagem Baixa / Calo, Escamação, Sulcos, / & $00: 10: 00$ & $00: 20: 00$ & $00: 40: 00$ \\
\hline Rolamento avariados) & $00: 16: 40$ & $00: 21: 00$ & $00: 25: 20$ \\
\hline CCT Médio & $00: 20: 00$ & $00: 25: 00$ & $00: 30: 00$ \\
\hline Substituição do Apoio do Engate & $00: 05: 00$ & $00: 07: 00$ & $00: 09: 00$ \\
\hline Substituição da Telha de Engate & & \\
\hline
\end{tabular}




\subsection{Definição do local e layout}

Conforme citado na seção 2.2, a realização das atividades de Manobra Zero / Pit Stop ocorrerá nas moegas 2 e 3, enquanto que as atividade de Fast Track serão realizadas no TPD. As atividades de reparo rápido (Manobra Zero / Pit Stop) serão realizadas conforme o layout apresentado na Figura 3.

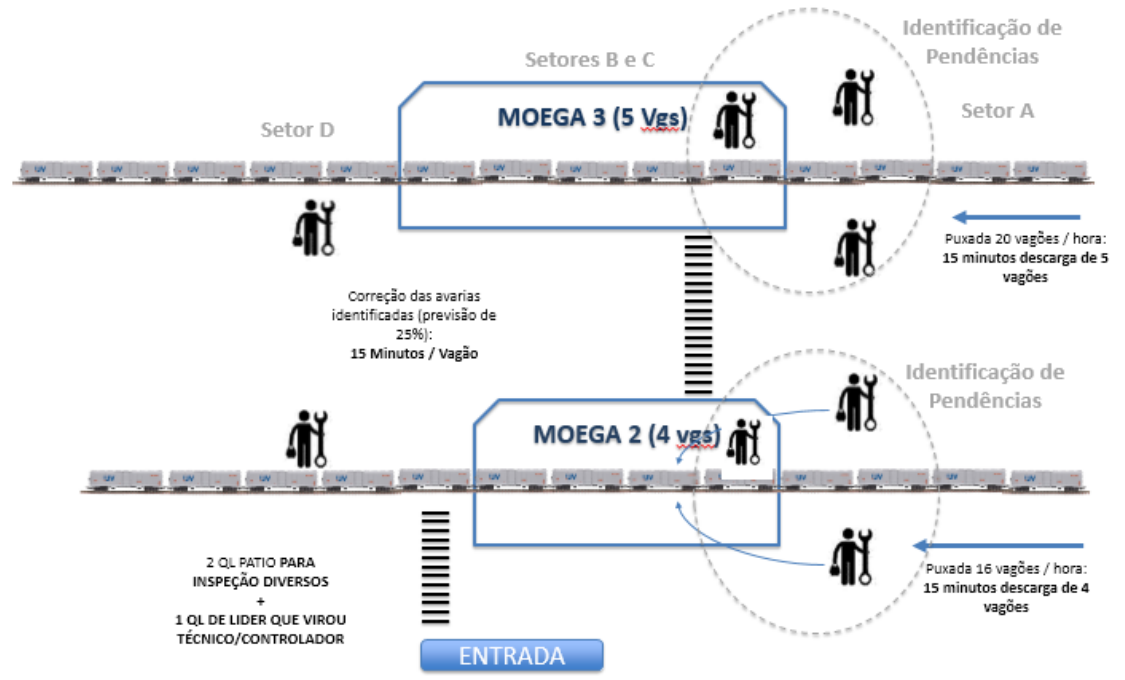

Figura 3. Layout de atividades na moega de Tubarão.

A moega 3 tem capacidade para 60 vagões, ocorrendo a puxada de 5 destes a cada 15 minutis, totalizando 20 vagões por hora. Na moega 2 a capacidade é de 80 vagões, com puxada de 4 a cada 15 minutos, totalizando 16 vagões por hora

As atividades de reparo médio (Fast Track) serão realizadas na linha do TPD, que foi reformado para atender as necessidades do novo sistema. O layout da área separada pode ser visto na Figura 3.

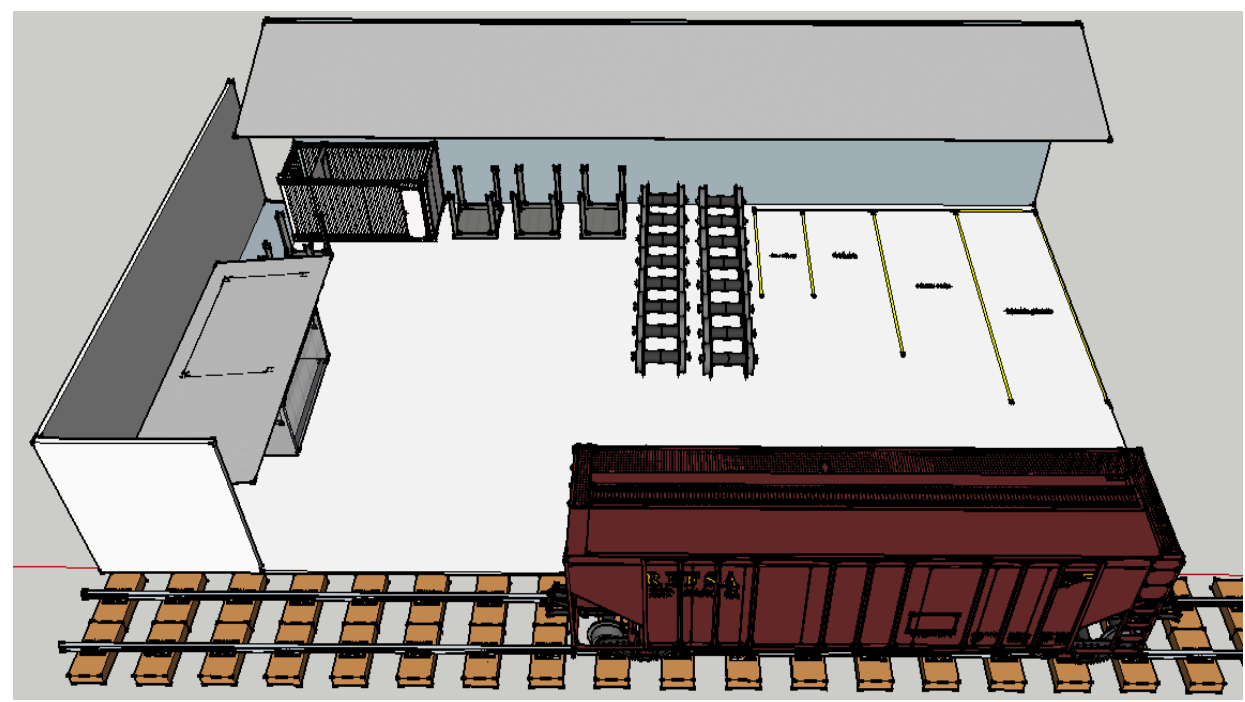

Figura 3. Layout Fast Track no TPD

O TPD tem capacidade de 30 vagões por linhas, tendo-se disponíveis 2 Inhas, a PD4 e PD5. Definiu-se junto a operadora do complexo portuário, a VALE, o tempo 
disponível para manutenção de 6 horas para o lote de 60 vagões. Em caso de puxada de outro lote de vagões antes do fim das 6 horas definidas é realizada a tomada de decisão pela manutenção sobre a liberação imediata dos vagões para recebimento do novo lote, ou a retenção do lote antigo até o fim do serviço.

\subsection{Definição dos recursos necessários}

De acordo com as atividades mapeadas para o projeto, e com o layout planejado e pronto para realização das atividades, foram realizadas visitas técnicas, consultorias para elaboração de especificações técnicas. A partir destas elaborou-se o plano de solicitação e aquisição dos equipamentos, conforme lista a seguir:

- Empilhadeira;

- Mesa pantográfica - equipamento de içamento;

- Caminhão Munk;

- Torre de iluminação;

- Caminhão oficina;

- Carro off-road.

Nas Tabelas 3 e 4 são apresentados quais equipamentos são utilizados em cada atividade.

Tabela 3. Equipamentos utilizados no Manobra Zero / Pit Stop

\begin{tabular}{|c|c|c|c|c|c|}
\hline MANOBRA ZERO / PIT STOP & $\begin{array}{l}\text { Carro Off } \\
\text { Road }\end{array}$ & $\begin{array}{l}\text { Caminhão } \\
\text { Oficina }\end{array}$ & $\begin{array}{l}\text { Caminhão } \\
\text { Munk }\end{array}$ & $\begin{array}{l}\text { Conjunto de } \\
\text { Içamento }\end{array}$ & Empilhadeira \\
\hline \multicolumn{6}{|l|}{ Freio Rápido } \\
\hline $\begin{array}{l}\text { Troca de Componentes de Freio (Torneiras Mangueiras, Mangueiras, Coletor de } \\
\text { Pó, Válvula de Alívio, Volante de Freio Manual) }\end{array}$ & $\mathrm{x}$ & & & & \\
\hline Reparação e/ou Substituição de DDV & $\mathrm{x}$ & & & & \\
\hline Reposição do Suporte Cego & $\mathrm{x}$ & & & & \\
\hline \multicolumn{6}{|l|}{ Truque Rápido } \\
\hline Substituição de Mola & $\mathrm{x}$ & & & & \\
\hline Substituição Setor de Graduação & $\mathrm{x}$ & & & & \\
\hline Substituição Barra de Compressão e/ou Chapa da Barra & $x$ & & & & \\
\hline Chavetas; & $\mathrm{x}$ & & & & \\
\hline Sapatas & $\mathrm{x}$ & & & & \\
\hline Realizar Graduação de Freio & $\mathrm{x}$ & & & & \\
\hline \multicolumn{6}{|l|}{ CCT Rápido } \\
\hline Reposição Pino da Mandíbula & $\mathrm{x}$ & & & & \\
\hline $\begin{array}{l}\text { Reparação e/ou Substituição de Alavanca de Corte e Acionamento (Haste de } \\
\text { Manobra) }\end{array}$ & $x$ & & & & \\
\hline
\end{tabular}

Tabela 4. Utilização dos equipamentos no Fast Track 


\begin{tabular}{|c|c|c|c|c|c|}
\hline FAST TRACK & $\begin{array}{c}\text { Carro Off } \\
\text { Road }\end{array}$ & $\begin{array}{c}\text { Caminhão } \\
\text { Oficina }\end{array}$ & $\begin{array}{l}\text { Caminhão } \\
\text { Munk }\end{array}$ & $\begin{array}{c}\text { Conjunto } \\
\text { de } \\
\text { Içamento }\end{array}$ & Empilhadeira \\
\hline \multicolumn{6}{|l|}{ Superestrutura Médio } \\
\hline Reparações com maçarico e soldas (Sem necessidade de trabalho em altura); & & $\mathrm{x}$ & & & $\mathrm{x}$ \\
\hline \multicolumn{6}{|l|}{ Freio Médio } \\
\hline Teste de Aplicação de Freio (Analise de Freio Isolado ou Não Aplica); & & $\mathrm{x}$ & & & \\
\hline Troca de Componentes de Freio (Conjunto de Válvulas, Ajustador), & & $\mathrm{x}$ & & & \\
\hline Substituição do Freio Manual & & $\mathrm{x}$ & & & \\
\hline Teste de Single Car (Para Corretiva); & & $\mathrm{x}$ & & & \\
\hline \multicolumn{6}{|l|}{ Truque Médio } \\
\hline Inspeção e/ ou Troca de Timoneria e Tirante de Freio do truque & & $\mathrm{x}$ & & & \\
\hline \multicolumn{6}{|l|}{ Rodeiro Médio } \\
\hline $\begin{array}{l}\text { Troca de Rodeiro por (Friso fino / Bandagem Baixa / Calo, Escamação, Sulcos, } \\
\text { / Rolamento avariados) }\end{array}$ & & $\mathrm{x}$ & $\mathrm{x}$ & $\mathrm{x}$ & $x$ \\
\hline \multicolumn{6}{|l|}{ CCT Médio } \\
\hline Substituição do Apoio do Engate & & $\mathrm{x}$ & & & \\
\hline Substituição da Telha de Engate & & $\mathrm{x}$ & & & \\
\hline
\end{tabular}

Diante das atividades levantadas, dimensionou-se a equipe necessária para funcionamento da estratégia na moega, que totaliza 37 colaboradores com as seguintes funções:

- 4 mecânicos por turno na moega 2, sendo 3 responsáveis por inspeção prévia e atendimento na moega e 1 responsável pelas manutenções rápidas após descarga dos vagões.

- 4 mecânicos por turno na moega 3, sendo 3 responsáveis por inspeção prévia e atendimento na moega e 2 responsável pelas manutenções rápidas após descarga dos vagões;

- 1 técnico/controlador, responsável pela apropriação e controle de processos das moegas 2 e 3, interface com operação da moega e CCP (Centro de Controle de Pátio) para acionamentos e atendimentos;

- 1 Inspetor responsável por toda operação de atendimento e check dos processos supracitados.

Além do dimensionado para as moegas há um efetivos de 9 colaboradores que fazem atendimento no pátio de Tubarão, sendo:

- 2 mecânicos por turno para inspeção de vagões diversos;

- 1 inspetor responsável por toda operação e atendimento dos processos.

Para atuação da frente de manutenção no TPD, dimensionou-se 16 colaboradores, sendo:

- 4 mecânicos por turno no TPD, responsáveis pelas manutenções de médio reparos, que não podem ser realizadas na moega;

\subsection{Plano de capacitação e certificação}

A partir da lista de atividades a serem realizadas, foi desenvolvida junto ao Centro de Especialização e Desenvolvimento (CED) a trilha técnica da nova função Fast Track, na qual consta todos os treinamentos internos e conhecimentos necessários aos executantes.

Diante da trilha técnica desenvolvida foram criadas instruções de trabalho em conjunto com a área de saúde e segurança, visando maior segurança operacional e 
dos colaboradores. Nestas constam cada etapa da realização da tarefa, com a descrição de como fazer, os possíveis desvios na tarefa e como sana-los.

Além dos treinamentos padrões da VLI para a mecânica, alguns dos colaboradores foram mapeados para treinamentos específicos de operação dos equipamentos adquiridos, especialização no processo de soldagem e inspeção de vagões no padrão utilizado pela Association of American Railroads (AAR - Associação das Ferrovias Americanas).

\section{RESULTADOS E DISCUSSÃO}

O objetivo do projeto em 2016 era que o piloto reduzisse em $45 \%$ o envio de vagões para oficina, com base no indicador anual. Após a implementação deste pode-se verificar que o objetivo foi cumprido, como pode ser visto abaixo no indicador de performance:

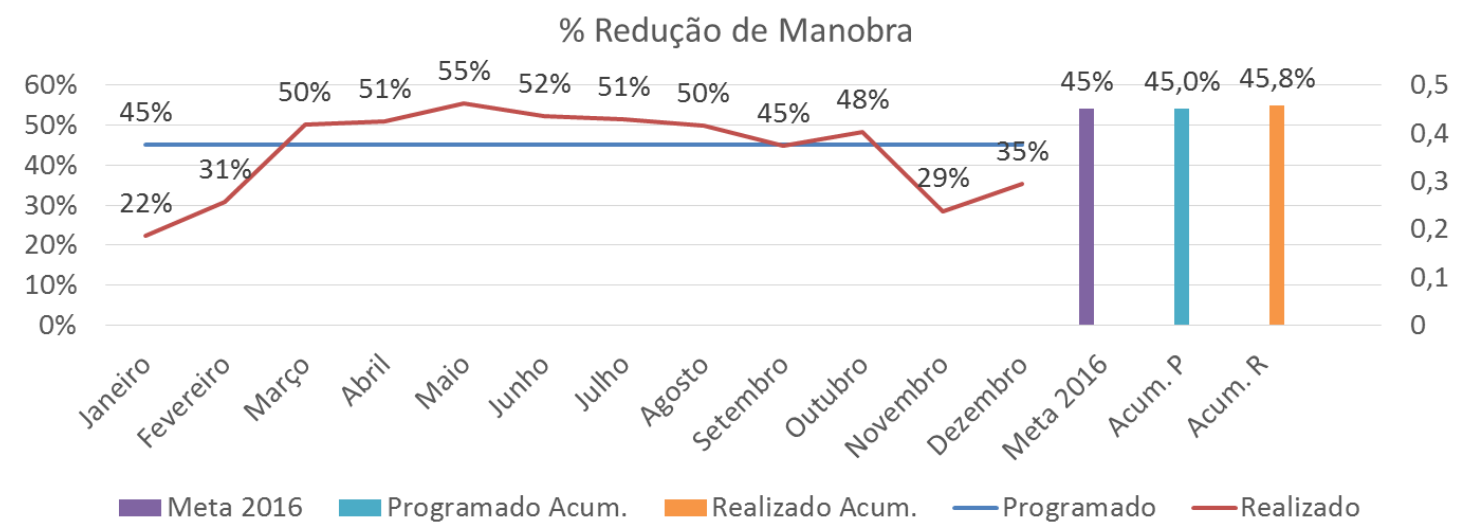

Figura 4. Indicador de redução percentual de manobras 2016

Obteve-se também uma redução de $36,5 \%$ na retenção de vagões, conforme pode ser visto na Figura 5:

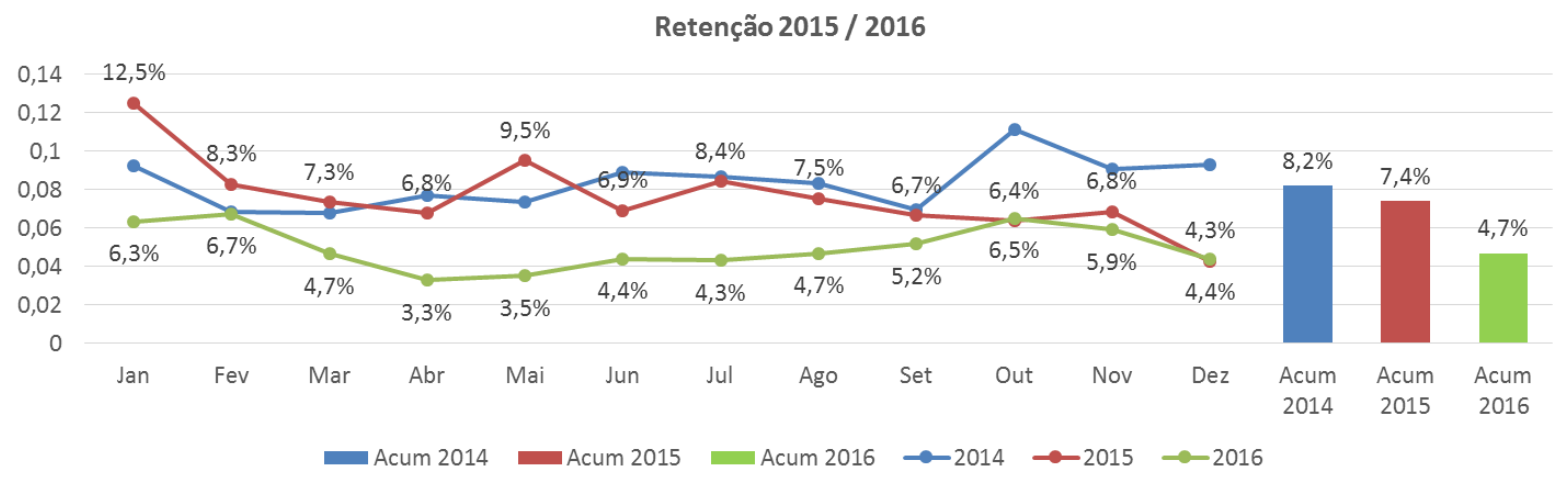

Figura 4. Indicador de retenção de vagões corredor $\mathrm{CL}$

A diminuição das manobras para oficina, somadas com a redução da retenção de vagões, geraram um ganho de mais de $0,44 \%$ na DF da frota de Grãos, reduzindo a 
necessidade de compra de 18 vagões, o que se traduz numa economia de mais de $\mathrm{R} \$ 5.074 .285,68$.

Somam-se a estes resultados os ganhos intangíveis, tais como a eliminação dos desperdícios em estoque, movimentos, espera, defeitos e processamento excessivo. $\mathrm{O}$ engajamento da equipe através das melhorias da condição de trbalho e $5 \mathrm{~S}$ e a implantação da metodologia de capacitação e certificação para operação dos equipamentos.

Em 2017 os ganhos matem-se acima do encontrado em 2016, com redução das manobras em 56,8\% no acumulado até Abril, como pode ser visto na Figura 5.

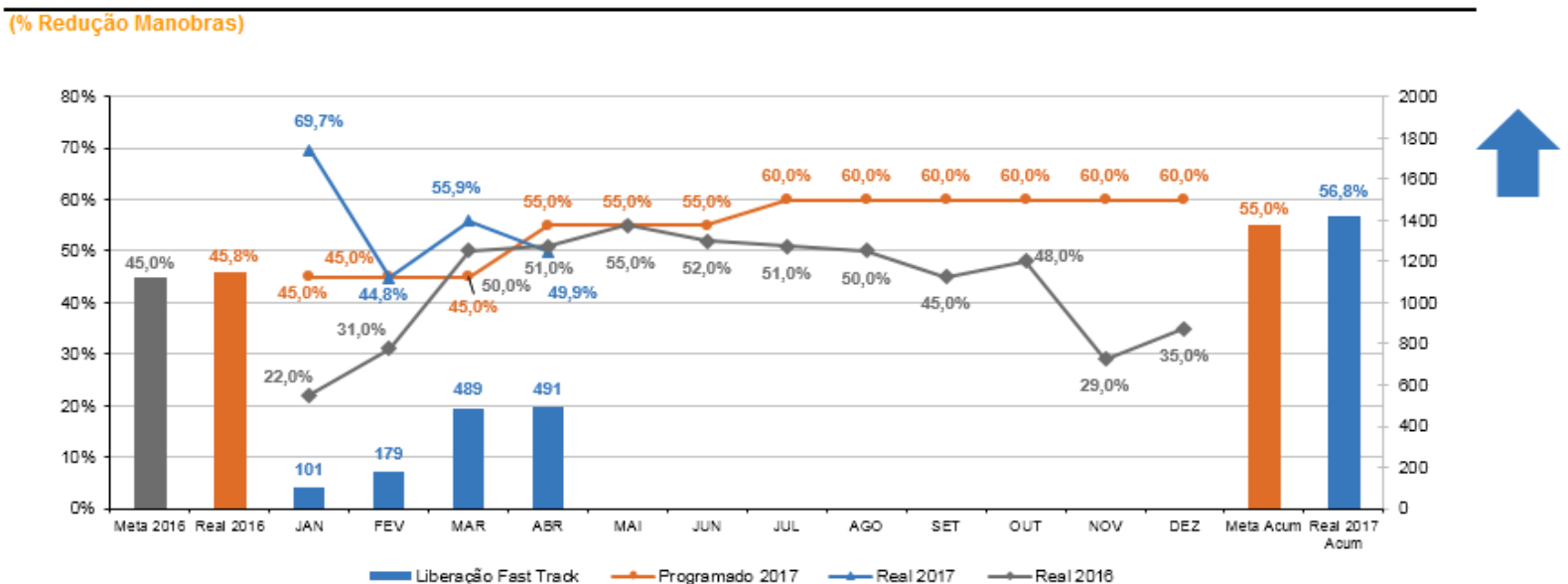

Figura 4. Figura 4. Indicador de redução percentual de manobras 2017

\section{CONCLUSÃo}

Este trabalho apresentou a metodologia de implantação do projeto piloto do Fast Track na VLI. Foram apresentados as 5 etapas do projeto, definição do local, definição da demanda de manutenção, definição do local e layout, definição dos recursos necessários e a criação dos plano de certificação e capacitação.

Através deste fica evidente os ganhos advindos da implantação do projeto, pois aproveitando o tempo morto durante a descarga de produtos pode-se atuar em uma ampla faixa de defeitos nos vagões, os quais só eram reparados em oficina. Através deste modelo obteve-se uma redução de $45,8 \%$ no envio de vagões para oficina em 2016, e em 2017 este numero já é de 56,8\%. 
Estas intervenções em pátio não só implicam em ganhos de disponibilidade de vagões, como também no aumento da confiabilidade, já que os ativos são inspecionados a cada descarga. Estes ganhos poderão ser vistos em uma análise de longo prazo, através do mapeamento das falhas em vagões manutenidos pelo Fast Track.

\section{REFERÊNCIAS}

1 Pinto AK, Xavier JN. Manutenção: função estratégica. $2^{\text {a }}$ Ed. Rio de Janeiro:

Qualitymark; 2001.

2 NBR 5462. Confiabilidade e Manutenabilidade. Rio de Janeiro: ABNT; 1994.

3 Lopes FJF. Apostila de Engenharia de Manutenção. Belo Horizonte: Programa de especialização em engenharia ferroviária PUC-MG; 2015.

4 Nepomuceno LX. Manutenção Preditiva em instalações industriais: Procedimento técnicos. São Paulo: Edgar Blucher; 1985.

5 Silva BD. DT 077 UFC - Estratégia de manutenção ferroviária da Logística. Rev - 2016 Divinópolis: VLI; 2016 